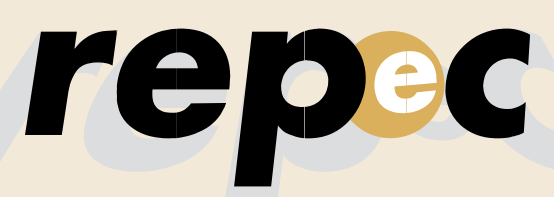

REPeC, Brasília, v. 10, n. 3, art. 1, p. 241-257, jul./set. 2016 Disponivel online em www.repec.org.br D0l: http://dx.doi.org/10.17524/repec.v10i3.1337
Revista de Educação e Pesquisa em Contabilidade Journal of Education and Research in Accounting

Periódico Trimestral, digital e gratuito publicado pela Academia Brasileira de Ciências Contábeis

ISSN 1981-8610

\title{
Comitê de Auditoria: adequação às regras da SOX, Bacen, Susep e IBGC
}

\section{Resumo}

O objetivo deste estudo foi identificar qual o nível de adequação dos comitês de auditoria das empresas dos níveis diferenciados da BM\&FBOVESPA às regras da SOX, Bacen, Susep e IBGC. A adequação foi analisada por meio de um check-list, construído com base nas principais normas e recomendações às quais as empresas brasileiras estão sujeitas. A análise pautouse nas seguintes características: composição, qualificação, mandato, quantidade de reuniões, atribuições e obrigações. A pesquisa se caracterizou como descritiva, predominantemente quantitativa e documental. Compreendeu 58 empresas e abrangeu 1.508 verificações que possibilitavam identificar o nível de adequação médio de $50 \%$ (13 de 26 questões), com a máxima de $88 \%$ (23 questões) e a mínima de $4 \%$ (1 questão). Os resultados apontaram que as instituições financeiras e as instituições de previdência e de seguros formam o grupo que está mais adequado às regras no que tange ao comitê de auditoria, enquanto as empresas submetidas à SOX e as demais apresentaram os índices mais baixos da amostra. Além disso, não se encontrou relação entre os níveis diferenciados de governança corporativa e o índice de adequação dos comitês, ou seja, possuir classificação no novo mercado não garante uma boa adequação às normas referentes ao comitê de auditoria.

Palavras-chave: Governança corporativa. Comitê de auditoria. Regras.

\begin{abstract}
Marina Schreiber de Abreu Siigor Sorrentino

Graduada em Ciências Contábeis pela Universidade Federal de Santa Catarina e Assistente Financeiro na Suiteplus Tecnologia da Informação e Consultores Ltda. Contato: Rua José Carlos Daux, 4756, bloco 2, sala 2. Bairro Saco Grande. Florianópolis-SC. CEP.: 88032-005. E-mail: marina.sorrentino@hotmail.com
\end{abstract}

\section{Bruna Teixeira}

Mestre em Contabilidade pela Universidade Federal de Santa Catarina e Contadora da Prefeitura Municipal de Balneário Camboriu (SC). Contato: Rua Dinamarca, 320. Bairro: Centro. CamboriuSC. CEP.: 88330-900.

E-mail: brunatteixeira@gmail.com

\section{Ernesto Fernando Rodrigues} Vicente

Doutor em Administração pela Universidade de São Paulo e Professor da Universidade Federal de Santa Catarina. Contato: Campus Trindade, CCN/CSE. Bairro Trindade. Florianópolis-SC. CEP.: 88040-900.

E-mail: ernesto.vicente@ufsc.br 


\section{Introdução}

Em decorrência dos escândalos financeiros de grandes empresas e da crise econômica de 2008, que trouxeram desconfiança ao mercado acionário de todo o mundo, é fundamental que se estude sobre estruturas de governança corporativa que ajudem a mitigar os conflitos de interesses e a assimetria informacional presente na relação entre acionista e gestor.

Nesse contexto, um mecanismo da governança corporativa reconhecido é o comitê de auditoria que, para Souza (2010, p.21), é "um dos pilares da reconstrução da credibilidade dos investidores nas demonstrações contábeis e demais informações sobre o desempenho operacional fornecidas pelas companhias de capital aberto ao mercado".

Apesar do conceito de comitê de auditoria ter surgido em 1930, criado pela New York Stock Exchange (NYSE), sua obrigatoriedade só foi definida em 2002 com a promulgação da Lei Sarbanes-Oxley (SOX). Para Santos (2009), a criação de normas legais está associada à necessidade de se obter a segurança exigida pelos cidadãos, que não estava sendo suprida apenas com a autorregulação.

No Brasil, após a SOX, e seguindo uma tendência mundial, os comitês de auditoria vêm se tornando, cada vez mais, uma obrigatoriedade legal, como nas determinações normativas do Conselho Monetário Nacional $(\mathrm{CMN})$, via Bacen e Conselho Nacional de Seguros Privados (CNSP), via Susep. Em complemento, há as orientações do Instituto Brasileiro de Governança Corporativa (IBGC) e da Comissão de Valores Mobiliários (CVM).

Essas entidades publicam normas orientando sobre as características necessárias que o comitê de auditoria deve possuir, ou seja, aspectos relacionados à sua composição, especialização, mandato e atribuições que contribuem para uma maior eficiência do órgão. No entanto, se têm-se evidências de que nem todos os comitês estão atendendo às referidas exigências.

Santos (2009), por exemplo, verificou uma grande quantidade de empresas que não praticam a regra de independência dos membros do comitê de auditoria, e Chiodini (2010) constatou a falta de especialista financeiro na maioria de sua amostra, contrariando as recomendações do IBGC. Pesquisas recentes sugerem que o comitê de auditoria, quando não constituídos de forma que atuem com independência, com acesso às informações e aconselhamento profissional e contenha membros alfabetizados financeiramente compromete, significativamente, o seu desempenho.

Assim, é importante que os acionistas e demais usuários conheçam a estrutura do comitê de auditoria da empresa de seu interesse, considerando que o comitê pode estar composto em desacordo com as regras vigentes, pode não estar atendendo às expectativas de que funciona como um elemento importante na mitigação dos problemas de agências e contribui para a confiabilidade e segurança das informações emitidas pela empresa. Essa situação pode comprometer a avaliação do risco inerente à informação contábil, prejudicando decisões quanto à compra, à venda, ou à manutenção de títulos corporativos, acarretando perdas financeiras.

Nesse sentido, considerando que o comitê de auditoria evidencia uma melhor prática de governança corporativa quando formado conforme as regras dos entes reguladores, é importante conhecer como se encontra a atual estrutura do comitê de auditoria nas empresas brasileiras. Dessa forma, o objetivo deste estudo é identificar qual o nível de adequação dos comitês de auditoria das empresas dos níveis diferenciados da BM\&FBOVESPA às regras da SOX, Bacen, Susep e IBGC. Para isso, formulou-se a seguinte pergunta de pesquisa: Qual o nível de adequação dos comitês de auditoria das empresas dos níveis diferenciados de governança da BM\&FBOVESPA às regras da SOX, Bacen, Susep e IBGC? 
Desse modo, espera-se que este estudo sirva de orientação para as empresas que ainda não possuem o comitê de auditoria e pretendem adequar-se às melhores práticas de governança corporativa; para as que o possuem, que analisem se atendem ao proposto pelas regras aplicadas a sua companhia; para os órgãos reguladores, que comparem o que é recomendado pelas demais entidades; para o mercado de capitais, que facilite o entendimento dos usuários por meio de maior transparência às informações; e para a academia, que contribua para as discussões sobre o tema. Ademais, a pesquisa se justifica por não ter sido localizado no Brasil estudo recente que verifique a estrutura do comitê, considerando todas as variáveis analisadas por este estudo.

\section{Referencial Teórico}

Segundo a Teoria da Agência de Jensen e Meckling (1976) na relação contratual em que uma ou mais pessoas (principal) transfere a outra pessoa (agente) o poder de decisão está repleto dos chamados problemas de agência decorrentes do conflito de interesse e da assimetria informacional presentes nessa relação.

Nesse sentido, é necessário que o principal (acionista) utilize de mecanismos de controle e monitoramento para evitar o comportamento inadequado do agente (gestor). Assim, a "governança corporativa pode ser vista como um conjunto de mecanismos que visam aumentar a probabilidade dos fornecedores de recursos garantirem para si o retorno sobre seu investimento" (Silveira, 2004, p.12).

Um mecanismo de destaque neste contexto é o comitê de auditoria. O papel do comitê de auditoria no sistema de governança é de atuar no intuito de proteção de interesses dos acionistas e demais partes que possuam interesse na organização. Segundo o IBGC (2009, p. 13) o comitê "deve agir no sentido de operacionalizar os deveres e responsabilidades da função de supervisão da gestão dos processos internos e assegurar a integridade e efetividade dos controles internos para a produção de relatórios financeiros". Além disso, o comitê busca assegurar a integridade do mercado de capitais (Peleias, Segreti, \& Costa, 2009) e desempenhar um papel de acompanhamento para assegurar a qualidade dos relatórios financeiros e responsabilidade corporativa (Carcello, \& Neal, 2000).

Segundo a empresa de auditoria e consultoria PricewatershouseCoopers (2007, p.30):

As exigências legais ou regulatórias para um Comitê de Auditoria variam entre os países - em alguns, elas são obrigatórias para companhias de capital aberto, em outros representam ações voluntárias. Adicionalmente, as responsabilidades de cada Comitê de Auditoria diferem, dependendo da cultura local e, em particular, das necessidades das companhias.

No Brasil, a obrigatoriedade se limita às empresas submetidas à SOX e às normas do Bacen e Susep, com algumas exceções. Após março de 2003, as empresas que operam no mercado americano e assim, estejam sob regulação da SOX podem substituir o Comitê de Auditoria pelo Conselho Fiscal desde que o conselho fiscal seja adaptado com as funções do comitê de auditoria (Furuta, 2010).

Em relação ao Bacen, instituições financeiras obrigadas se limitam àquelas que apresentem, no encerramento dos dois últimos exercícios sociais, patrimônio de referência igual ou superior a um bilhão de reais; ou administração de recursos de terceiros em montante igual ou superior a um bilhão de reais; ou o somatório das captações de depósitos e de administração de recursos de terceiros em montante igual ou superior a cinco bilhões de reais (Banco Central do Brasil, Resolução n. ${ }^{\circ} 3.198,2004$ ). 
E, para as instituições de previdência e de seguros submetidas à Susep, a determinação é para as que apresentem, no encerramento dos dois últimos exercícios sociais, Patrimônio Líquido Ajustado igual ou superior a quinhentos milhões de reais ou Provisões Técnicas em montante igual ou superior a setecentos milhões de reais (Conselho Nacional de Seguros Privados, Resolução n. ${ }^{\circ} 118,2004$ ). As empresas que não se enquadram nesses grupos, portanto, tem a constituição do comitê de auditoria recomendado e orientado pela CVM e pelo Instituto Brasileiro de Governança Corporativa (IBGC).

Cada ente, portanto, possui seu conjunto de determinantes para a formação e funcionamento do comitê de auditoria. Para melhor compreensão das semelhanças e diferenças, a Figura 1 faz a comparação entre as regras da SOX, Bacen, Susep e as orientações do IBGC. As recomendações da CVM que se dirigem ao comitê de auditoria não contam na Figura 1, pois se resumem em aspectos relacionados à composição dos membros: devem ter pelo menos um representante dos minoritários e pelo menos dois membros devem possuir experiência em finanças.

\begin{tabular}{|c|c|c|c|c|}
\hline & sox & Bacen (*) & $\operatorname{IBGC}\left({ }^{* *}\right)$ & Susep $(* * *)$ \\
\hline \multirow{2}{*}{ 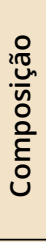 } & $\begin{array}{l}\text { Membros independentes } \\
\text { do Conselho de } \\
\text { Administração }\end{array}$ & $\begin{array}{l}\text { Membros independentes. } \\
\text { Não pode ser formado por } \\
\text { membros do Conselho } \\
\text { Fiscal }\end{array}$ & $\begin{array}{l}\text { Membros independentes, } \\
\text { com pelo menos um } \\
\text { representante dos } \\
\text { minoritários }\end{array}$ & Não faz referência \\
\hline & Não faz referência & $\begin{array}{l}\text { Mínimo, por três } \\
\text { integrantes }\end{array}$ & Não faz referência & $\begin{array}{l}\text { Mínimo, por três } \\
\text { integrantes }\end{array}$ \\
\hline 疍 & $\begin{array}{l}\text { Pelo menos um dos } \\
\text { membros seja um } \\
\text { especialista financeiro }\end{array}$ & $\begin{array}{l}\text { Pelo menos um } \\
\text { dos membros deve } \\
\text { possuir comprovados } \\
\text { conhecimentos nas } \\
\text { áreas de contabilidade e } \\
\text { auditoria }\end{array}$ & $\begin{array}{l}\text { Todos com conhecimentos } \\
\text { básicos de contabilidade } \\
\text { e finanças, sendo um com } \\
\text { maior experiência em } \\
\text { contabilidade e auditoria } \\
\text { ou gestão financeira }\end{array}$ & $\begin{array}{l}\text { Pelo menos um dos } \\
\text { integrantes deve } \\
\text { possuir comprovados } \\
\text { conhecimentos nas } \\
\text { áreas de contabilidade e } \\
\text { auditoria }\end{array}$ \\
\hline $\begin{array}{l}\stackrel{0}{\pi} \\
\substack{0 \\
\frac{c}{c}} \\
\frac{\pi}{\pi}\end{array}$ & $\begin{array}{l}\text { Não faz referência } \\
\text { explícita }\end{array}$ & $\begin{array}{l}\text { Permanência máxima de } \\
\text { cinco anos com retorno } \\
\text { após três anos }\end{array}$ & $\begin{array}{l}\text { Pode ser limitado por meio } \\
\text { de rodízio automático }\end{array}$ & $\begin{array}{l}\text { Permanência máxima de } \\
\text { cinco anos com retorno } \\
\text { após três anos }\end{array}$ \\
\hline \multirow[b]{2}{*}{ 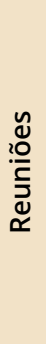 } & $\begin{array}{l}\text { Os auditores deverão } \\
\text { encaminhar relatório } \\
\text { específico para o comitê }\end{array}$ & $\begin{array}{l}\text { Determina a realização de } \\
\text { reuniões periódicas com } \\
\text { os auditores }\end{array}$ & Reuniões com os auditores & $\begin{array}{l}\text { Reunir-se, no mínimo } \\
\text { trimestralmente, com os } \\
\text { auditores independentes }\end{array}$ \\
\hline & Não faz referência & $\begin{array}{l}\text { Reunir-se, no mínimo, } \\
\text { trimestralmente com os } \\
\text { auditores }\end{array}$ & $\begin{array}{l}\text { Reunir-se regularmente } \\
\text { com o Conselho de } \\
\text { Administração, o Conselho } \\
\text { Fiscal (quando instalado), } \\
\text { o diretor-presidente e } \\
\text { demais diretores }\end{array}$ & $\begin{array}{l}\text { Reunir-se, no mínimo, } \\
\text { trimestralmente com os } \\
\text { auditores }\end{array}$ \\
\hline
\end{tabular}




\begin{tabular}{|c|c|c|c|c|}
\hline & sox & Bacen (*) & IBGC (**) & Susep $(* * *)$ \\
\hline \multirow{7}{*}{ 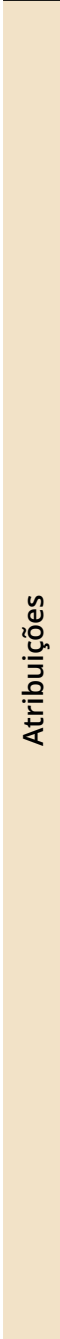 } & $\begin{array}{l}\text { Responsabilidade pela } \\
\text { contratação e substituição } \\
\text { do auditor }\end{array}$ & $\begin{array}{l}\text { Recomendar a entidade } \\
\text { a ser contratada para } \\
\text { prestação dos serviços de } \\
\text { auditoria externa }\end{array}$ & $\begin{array}{l}\text { Recomendar a contratação, } \\
\text { remuneração, retenção } \\
\text { e substituição do auditor } \\
\text { independente }\end{array}$ & $\begin{array}{l}\text { Recomendar a contratação } \\
\text { e substituição do auditor } \\
\text { independente }\end{array}$ \\
\hline & $\begin{array}{l}\text { Todos os serviços de } \\
\text { auditoria e os não serviços } \\
\text { devem ser pré-aprovados } \\
\text { pelo comitê }\end{array}$ & Não faz referência & Não faz referência & Não faz referência \\
\hline & $\begin{array}{l}\text { Supervisionar os } \\
\text { processos de elaboração, } \\
\text { divulgação e auditoria } \\
\text { das demonstrações } \\
\text { financeiras }\end{array}$ & $\begin{array}{l}\text { Revisar as demonstrações } \\
\text { contábeis semestrais, } \\
\text { inclusive notas } \\
\text { explicativas e relatórios da } \\
\text { administração }\end{array}$ & Não faz referência & $\begin{array}{l}\text { Revisar, as demonstrações } \\
\text { contábeis semestralmente, } \\
\text { inclusive notas explicativas, } \\
\text { relatórios da administração } \\
\text { e parecer do auditor } \\
\text { independente }\end{array}$ \\
\hline & $\begin{array}{l}\text { Determinar conjunto } \\
\text { de procedimentos } \\
\text { internos para assegurar a } \\
\text { evidenciação contábil }\end{array}$ & $\begin{array}{l}\text { Responsável pela revisão } \\
\text { da eficácia e eficiência dos } \\
\text { controles internos e riscos }\end{array}$ & Controle interno e riscos & $\begin{array}{l}\text { Verificar o cumprimento } \\
\text { de dispositivos legais } \\
\text { e normativos, além de } \\
\text { regulamentos e códigos } \\
\text { internos }\end{array}$ \\
\hline & Não faz referência & $\begin{array}{l}\text { Avaliar o cumprimento, } \\
\text { pela administração } \\
\text { da instituição, das } \\
\text { recomendações } \\
\text { feitas pelos auditores } \\
\text { independentes ou } \\
\text { internos }\end{array}$ & $\begin{array}{l}\text { Acompanhar as } \\
\text { recomendações dos } \\
\text { auditores externos e } \\
\text { internos }\end{array}$ & $\begin{array}{l}\text { Avaliar o cumprimento } \\
\text { ou a justificativa para } \\
\text { o descumprimento } \\
\text { das recomendações } \\
\text { feitas pelos auditores } \\
\text { independentes ou pelos } \\
\text { auditores internos }\end{array}$ \\
\hline & $\begin{array}{l}\text { Adoção pela empresa de } \\
\text { um código de ética para } \\
\text { administradores }\end{array}$ & Não faz referência & $\begin{array}{l}\text { Zelar pelo cumprimento do } \\
\text { código de conduta }\end{array}$ & $\begin{array}{l}\text { Estabelecer e divulgar } \\
\text { regulamentos e códigos } \\
\text { internos }\end{array}$ \\
\hline & $\begin{array}{l}\text { Adotar procedimentos } \\
\text { para receber e tratar } \\
\text { de queixas relativas à } \\
\text { contabilidade, controles } \\
\text { internos e auditoria }\end{array}$ & Não faz referência & Não faz referência & Não faz referência \\
\hline \multirow{2}{*}{ 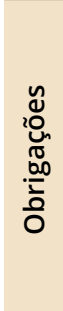 } & $\begin{array}{l}\text { Não faz referência ao } \\
\text { relatório do comitê }\end{array}$ & $\begin{array}{l}\text { Deve elaborar o relatório } \\
\text { de comitê de auditoria }\end{array}$ & Não faz referência & $\begin{array}{l}\text { Deve elaborar, ao final dos } \\
\text { semestres, o relatório de } \\
\text { comitê de auditoria }\end{array}$ \\
\hline & Sem referência específica & $\begin{array}{l}\text { Deve possuir regras } \\
\text { para seu próprio } \\
\text { funcionamento aprovadas } \\
\text { pelo Conselho de } \\
\text { Administração }\end{array}$ & $\begin{array}{l}\text { Deve adotar regimento } \\
\text { interno }\end{array}$ & $\begin{array}{l}\text { Deve possuir regras para } \\
\text { seu próprio funcionamento } \\
\text { aprovadas pelo Conselho } \\
\text { de Administração }\end{array}$ \\
\hline
\end{tabular}

${ }^{*}$ ) Com base na Resolução n. ${ }^{\circ}$ 3.198/2004; (**) Com base no Código de Melhores Práticas de Governança Corporativa; $(* * *)$ Com base na Resolução CNSP n. ${ }^{\circ} 118 / 2004$.

Fonte: adaptado de Santos (2009).

Figura 1. Comitê de auditoria: Comparativo entre a SOX e as regras brasileiras 
Observa-se que, com exceção da Susep, que não faz referência, as demais entidades destacam que é desejável que o comitê de auditoria seja composto totalmente por membros independentes. Bronson, Carcello, Hollingsworth e Neal (2009) analisaram se a composição do comitê totalmente independente é relevante para a obtenção de resultados eficazes de monitoramento, para amenizar as exigências estabelecidas pela Lei Sarbanes-Oxley (SOX). A pesquisa apontou que os benefícios em relação à composição do comitê de auditoria são auferidos somente quando esse órgão é completamente independente. Dessa forma, os resultados fornecem suporte para a referida exigência.

A presença do especialista financeiro pode impactar de forma positiva a empresa. Felo, Krishnamurthy e Solieri (2003) concluíram que há uma correlação positiva entre o percentual de membros especialistas na área financeira do comitê de auditoria e a qualidade da divulgação financeira, ou seja, quanto maior o número de especialistas na área financeira que compõem o comitê de auditoria, melhor a qualidade da divulgação financeira da empresa.

Outras pesquisas que apontam a relação positiva pela presença de um especialista financeiro são as de Sharma, Naiker e Lee (2009) e Raghunandan e Rama (2007), que encontraram indícios de que a presença de um especialista financeiro está, positivamente, relacionada com a frequência das reuniões do comitê de auditoria, uma vez que esses especialistas fornecem um monitoramento efetivo aos relatórios financeiros.

Com relação à questão temporal, ou seja, tempo de duração do mandato e quantidade de horas empregadas ao trabalho, o Art. 12 do Banco Central do Brasil, Resolução n. ${ }^{\circ} .198$ (2004), estabelece que o mandato dos membros do Comitê de Auditoria deve ser de no máximo, cinco anos, excetuando-se as companhias de capital fechado que não necessitam de mandato fixo para os conselheiros do comitê; e que o integrante do Comitê de Auditoria somente pode voltar a integrar tal órgão na mesma instituição depois de decorridos, no mínimo, três anos do final do seu mandato.

Sobre as atribuições do comitê de auditoria, elas podem variar de acordo com o cenário de cada empresa (Peleias et al., 2009) Em geral, é função do comitê de auditoria contratar, compensar e supervisionar a firma de auditoria independente que irá preparar os relatórios de auditoria e trabalhos relacionados; responde, ainda, pela resolução de quaisquer conflitos que possam existir sobre relatórios contábeis entre a administração e os auditores independentes (Furuta, 2010; Santos, 2009).

Também no que concerne às atribuições, Carcello, Hermanson e Neal (2002), ao analisarem 150 relatórios que descrevem as atividades executadas pelo comitê de auditoria, constataram alta conformidade entre o que é obrigatório nas funções do comitê de auditoria com o que é divulgado em seus relatórios, como informações relacionadas à revisão e a discussão das demonstrações financeiras com a gestão. Contudo, a divulgação voluntária de atividades do comitê de auditoria foi mais comum para instituições financeiras, grandes empresas, companhias listadas na New York Stock Exchange (NYSE) e empresas com maior número de membros independentes no comitê.

Em relação ao relatório elaborado pelo comitê de auditoria, este visa determinar a responsabilidade da administração por estabelecer e manter esses controles; identificar o padrão de análise usado pela administração para a avaliação da efetividade dos controles; conter uma avaliação da efetividade dos controles internos relacionados na data-base de emissão do parecer de auditoria; e incluir o relatório de atestação do auditor independente sobre a declaração da administração, como parte integrante da auditoria (Souza, 2010). A ausência ou atuação ineficaz do comitê de auditoria é considerada uma falha a ser apontada no parecer do auditor independente. 


\section{Metodologia}

Esta pesquisa caracteriza-se como descritiva, que, de acordo com Gil (2002, p. 42), "tem como objetivo primordial a descrição das características de determinada população ou fenômeno ou, então, o estabelecimento de relações entre variáveis". Quanto aos procedimentos, a pesquisa se caracteriza como documental, na qual, conforme Lakatos e Marconi (2001, p. 174), “a fonte de coleta de dados está restrita a documentos escritos ou não". Neste estudo, a pesquisa documental pautou-se nas informações disponibilizadas no site da BM\&FBOVESPA e no sítio eletrônico das empresas.

No que concerne à abordagem do problema, houve o levantamento de quantidades de itens evidenciados que foram quantificados tanto na coleta dos dados quanto no tratamento dos resultados, caracterizando uma abordagem predominantemente quantitativa (Richardson, 2008).

Primeiramente, fez-se um levantamento bibliográfico em revistas científicas, banco de dados de teses e dissertações e congressos da área contábil para elaboração do referencial teórico e análise dos estudos anteriores para conhecimento do tema. Em seguida, elaborou-se um comparativo para auxiliar na compreensão das semelhanças e diferenças estabelecidas pela SOX, normas do Bacen e Susep e as orientações do IBGC. A análise pautou-se nas características do comitê de auditoria que foram classificadas nas categorias: composição, qualificação, mandato, quantidade de reuniões, atribuições e obrigações.

Com base na Figura 1, foi elaborado um check-list com 26 questões. A análise dos dados provenientes da aplicação do check-list foi realizada em dois passos.

Primeiro, verificou-se a aderência das características do comitê de auditoria de cada empresa, considerando a regra que esta deve adotar. Constatou-se que algumas instituições financeiras da amostra possuem ADRs, logo, estas devem atender ao Bacen e SOX, conjuntamente. Para as empresas desobrigadas a constituir o comitê de auditoria, considerou-se que estas devem atender, no mínimo, as recomendações do IBGC. Dessa forma dividiu-se as empresas selecionadas em cinco grupos (SOX, Bacen, SOX e Bacen, Susep e IBGC), o que permitiu verificar a adequação do comitê de auditoria em uma análise direcionada à regra pertinente a cada empresa. Foi atribuído "sim", se atende a determinado item, e "não", se não atende. Quando não foram encontradas evidências sobre determinada questão nas informações disponíveis no site da BM\&FBOVESPA, tanto quanto no site da própria empresa, foi atribuída à expressão "não consta" (N/C).

No segundo passo, criou-se um índice para identificar o nível de adequação dos comitês de auditoria às regras analisadas e assim responder à pergunta de pesquisa. $\mathrm{O}$ índice foi criado atribuindo, para cada "sim" do check-list, o dígito 1 e, para cada "não", o dígito 0 , sendo a soma dos itens o índice procurado. Adicionalmente, foi verificado o nível de governança de cada companhia e avaliado se existe relação com o índice encontrado, por meio da análise quartil.

A população selecionada é composta pelas empresas pertencentes aos segmentos especiais de listagem da BM\&FBOVESPA. A escolha desse grupo se justifica pelas empresas pertencentes a esses segmentos estarem sujeitas a rígidas regras de governança corporativa (BM\&FBOVESPA, 2014). Visto que o comitê de auditoria compõe o conjunto de melhores práticas da governança corporativa, esperou-se encontrar a presença do comitê em maior quantidade nessas companhias.

No universo de 207 empresas ( 9 do Bovespa Mais, 145 do Novo Mercado, 20 do Nível 2 e 43 do Nível 1), constatou-se que 66 delas possuíam comitê de auditoria no exercício de 2013 . O ano de 2013 foi escolhido por ser o último ano de informações disponíveis sobre o comitê de auditoria. Dessas empresas, foram desconsideradas oito, por apresentarem dados incompletos ou referentes ao ano de 2014. Assim, a população selecionada resultou em 58 empresas, sendo 39 empresas listadas no Novo Mercado, 11 empresas no Nível 1 e 8 empresas no Nível 2 dos Níveis Diferenciados de Governança Corporativa.

Uma limitação do estudo está relacionada com a análise dos dados, que foi elaborada com base nas informações divulgadas pelas empresas, mas que não abrange, necessariamente, todos os aspectos relacionados ao comitê de auditoria, apenas os que são verificáveis por meio da análise das informações disponíveis ao público. 


\section{Análise e resultados da pesquisa}

Neste tópico, serão apresentados a análise dos dados e o resultado da pesquisa referente à Composição, Qualificação, Mandato, Reuniões, Atribuições e Obrigações do Comitê de Auditoria e o nível de adequação à Governança Corporativa.

A Tabela 1 apresenta os dados referentes à composição do comitê de auditoria das 58 empresas da população selecionada.

Tabela 1

Composição do Comitê de Auditoria

\begin{tabular}{|c|c|c|c|c|c|c|c|c|c|c|c|c|c|}
\hline \multirow{2}{*}{$\mathbf{N}^{\circ}$} & \multirow{2}{*}{ Questões } & \multicolumn{2}{|c|}{ sox } & \multicolumn{2}{|c|}{ Bacen } & \multicolumn{2}{|c|}{ sox e Bacen } & \multicolumn{2}{|c|}{ Susep } & \multicolumn{2}{|c|}{ IBGC } & \multicolumn{2}{|c|}{ Total } \\
\hline & & Sim & Não & Sim & Não & Sim & Não & Sim & Não & Sim & Não & Sim & Não \\
\hline 1 & $\begin{array}{l}\text { O comitê de } \\
\text { auditoria possui } \\
\text { pelo menos } 3 \text { (três) } \\
\text { membros? }\end{array}$ & $\begin{array}{c}15 \\
75 \%\end{array}$ & $\begin{array}{c}5 \\
25 \%\end{array}$ & $\begin{array}{c}8 \\
100 \%\end{array}$ & $\begin{array}{c}0 \\
0 \%\end{array}$ & $\begin{array}{c}5 \\
100 \%\end{array}$ & $\begin{array}{c}0 \\
0 \%\end{array}$ & $\begin{array}{c}2 \\
100 \%\end{array}$ & $\begin{array}{c}0 \\
0 \%\end{array}$ & $\begin{array}{c}19 \\
83 \%\end{array}$ & $\begin{array}{c}4 \\
17 \%\end{array}$ & $\begin{array}{c}49 \\
84 \%\end{array}$ & $\begin{array}{c}9 \\
16 \%\end{array}$ \\
\hline 2 & $\begin{array}{l}\text { Os membros são } \\
\text { independentes? }\end{array}$ & $\begin{array}{c}1 \\
16 \%\end{array}$ & $\begin{array}{c}19 \\
84 \%\end{array}$ & $\begin{array}{c}2 \\
38 \%\end{array}$ & $\begin{array}{c}6 \\
62 \%\end{array}$ & $\begin{array}{c}3 \\
60 \%\end{array}$ & $\begin{array}{c}2 \\
40 \%\end{array}$ & $\begin{array}{c}0 \\
0 \%\end{array}$ & $\begin{array}{c}2 \\
100 \%\end{array}$ & $\begin{array}{c}2 \\
9 \%\end{array}$ & $\begin{array}{c}21 \\
91 \%\end{array}$ & $\begin{array}{c}8 \\
14 \%\end{array}$ & $\begin{array}{c}50 \\
86 \%\end{array}$ \\
\hline 3 & $\begin{array}{l}\text { Existem membros } \\
\text { que também são do } \\
\text { conselho fiscal? }\end{array}$ & $\begin{array}{c}1 \\
5 \%\end{array}$ & $\begin{array}{c}19 \\
95 \%\end{array}$ & $\begin{array}{c}0 \\
0 \%\end{array}$ & $\begin{array}{c}8 \\
100 \%\end{array}$ & $\begin{array}{c}0 \\
0 \%\end{array}$ & $\begin{array}{c}5 \\
100 \%\end{array}$ & $\begin{array}{c}0 \\
0 \%\end{array}$ & $\begin{array}{c}2 \\
100 \%\end{array}$ & $\begin{array}{c}0 \\
0 \%\end{array}$ & $\begin{array}{c}23 \\
100 \%\end{array}$ & $\begin{array}{c}1 \\
2 \%\end{array}$ & $\begin{array}{c}57 \\
98 \%\end{array}$ \\
\hline
\end{tabular}

Fonte: dados da pesquisa (2015).

Observa-se na questão 1 que, em $84 \%$, ou 49 empresas selecionadas, o comitê de auditoria é composto por, no mínimo, três membros, logo, atende às recomendações sobre a governança corporativa, observadas nas normas emitidas pelo Bacen e pela Susep. Cinco empresas submetidas à SOX e quatro empresas desobrigadas a constituírem o comitê de auditoria não atendem a essa prerrogativa. Vale destacar que a SOX não faz menção à quantidade de membros.

Na questão 2, com relação à independência dos membros em $86 \%$, ou 50 empresas do total da população selecionada, os integrantes do comitê de auditoria não são independentes. Esse resultado corrobora os achados de Silveira e Ito (2008) e Santos (2009), que também identificaram, no ano de 2007 e 2008 , respectivamente, que grande parte dos comitês de auditoria possui membros que não são independentes. Como regra, a SOX e o Bacen exigem que as empresas possuam integrantes independentes no comitê de auditoria, sendo assim, seis entidades financeiras, 19 empresas que possuem ADRs e 2 entidades financeiras que possuem ações negociáveis no mercado americano estão em desacordo com as exigências normativas. Além disso, 21 outras organizações estão inadequadas a essa regra.

No que se refere à questão 3 , sobre a existência de membros do comitê de auditoria que também constituem o conselho fiscal, $98 \%$, ou 57 empresas do total da população selecionada, não fazem parte do conselho fiscal. O resultado mostra que apenas uma empresa, a JBS, que está sujeita à SOX, não atende a esse requisito. Vale destacar que essa exigência é feita pelo Bacen.

De acordo com a recomendação do IBGC, entre os membros independentes que compõem o comitê de auditoria, pelo menos um membro deverá ser representante dos minoritários. Atenta-se que nenhuma empresa da amostra atende à exigência ou não divulgam essa informação. 
A Tabela 2 apresenta a qualificação do comitê de auditoria das 58 empresas que compõem a população selecionada do estudo.

Tabela 2

Qualificação do Comitê de Auditoria

\begin{tabular}{|c|c|c|c|c|c|c|c|c|c|c|c|c|c|}
\hline \multirow{2}{*}{$\mathbf{N}^{\circ}$} & \multirow{2}{*}{ Questões } & \multicolumn{2}{|c|}{ sox } & \multicolumn{2}{|c|}{ Bacen } & \multicolumn{2}{|c|}{ sox e Bacen } & \multicolumn{2}{|c|}{ Susep } & \multicolumn{2}{|c|}{ IBGC } & \multicolumn{2}{|c|}{ Total } \\
\hline & & Sim & Não & Sim & Não & Sim & Não & Sim & Não & Sim & Não & Sim & Não \\
\hline 1 & $\begin{array}{l}\text { Pelo menos um dos } \\
\text { membros é especialista } \\
\text { financeiro? }\end{array}$ & $\begin{array}{c}14 \\
70 \%\end{array}$ & $\begin{array}{c}6 \\
30 \%\end{array}$ & $\begin{array}{c}7 \\
88 \%\end{array}$ & $\begin{array}{c}1 \\
13 \%\end{array}$ & $\begin{array}{c}5 \\
100 \%\end{array}$ & $\begin{array}{c}0 \\
0 \%\end{array}$ & $\begin{array}{c}1 \\
50 \%\end{array}$ & $\begin{array}{c}1 \\
50 \%\end{array}$ & $\begin{array}{c}16 \\
70 \%\end{array}$ & $\begin{array}{c}7 \\
30 \%\end{array}$ & $\begin{array}{c}43 \\
74 \%\end{array}$ & $\begin{array}{c}15 \\
26 \%\end{array}$ \\
\hline 2 & $\begin{array}{l}\text { Pelo menos um dos } \\
\text { membros tem conhecimento } \\
\text { na área de contabilidade e } \\
\text { auditoria? }\end{array}$ & $\begin{array}{c}9 \\
45 \%\end{array}$ & $\begin{array}{c}11 \\
55 \%\end{array}$ & $\begin{array}{c}7 \\
88 \%\end{array}$ & $\begin{array}{c}1 \\
13 \%\end{array}$ & $\begin{array}{c}5 \\
100 \%\end{array}$ & $\begin{array}{c}0 \\
0 \%\end{array}$ & $\begin{array}{c}2 \\
100 \%\end{array}$ & $\begin{array}{c}0 \\
0 \%\end{array}$ & $\begin{array}{c}15 \\
65 \%\end{array}$ & $\begin{array}{c}8 \\
35 \%\end{array}$ & $\begin{array}{c}38 \\
66 \%\end{array}$ & $\begin{array}{c}20 \\
34 \%\end{array}$ \\
\hline 3 & $\begin{array}{l}\text { Todos os membros possuem } \\
\text { conhecimentos básicos em } \\
\text { contabilidade e finanças? }\end{array}$ & $\begin{array}{c}6 \\
30 \%\end{array}$ & $\begin{array}{c}14 \\
70 \%\end{array}$ & $\begin{array}{c}1 \\
13 \%\end{array}$ & $\begin{array}{c}7 \\
88 \%\end{array}$ & $\begin{array}{c}5 \\
100 \%\end{array}$ & $\begin{array}{c}0 \\
0 \%\end{array}$ & $\begin{array}{c}1 \\
50 \%\end{array}$ & $\begin{array}{c}1 \\
50 \%\end{array}$ & $\begin{array}{c}6 \\
26 \%\end{array}$ & $\begin{array}{c}17 \\
74 \%\end{array}$ & $\begin{array}{c}19 \\
33 \%\end{array}$ & $\begin{array}{c}39 \\
67 \%\end{array}$ \\
\hline 4 & $\begin{array}{l}\text { Os comitês possuem pelo } \\
\text { menos um membro com } \\
\text { maior experiência em } \\
\text { contabilidade e auditoria ou } \\
\text { gestão financeira? }\end{array}$ & $\begin{array}{c}14 \\
70 \%\end{array}$ & $\begin{array}{c}6 \\
30 \%\end{array}$ & $\begin{array}{c}8 \\
100 \%\end{array}$ & $\begin{array}{c}0 \\
0 \%\end{array}$ & $\begin{array}{c}5 \\
100 \%\end{array}$ & $\begin{array}{c}0 \\
0 \%\end{array}$ & $\begin{array}{c}2 \\
100 \%\end{array}$ & $\begin{array}{c}0 \\
0 \%\end{array}$ & $\begin{array}{c}19 \\
83 \%\end{array}$ & $\begin{array}{c}4 \\
17 \%\end{array}$ & $\begin{array}{c}48 \\
83 \%\end{array}$ & $\begin{array}{c}10 \\
17 \%\end{array}$ \\
\hline
\end{tabular}

Fonte: dados da pesquisa (2015).

Verifica-se, na questão 1, que 74\%, ou 43 empresas da população selecionada, apresentam pelo menos um especialista financeiro. O resultado corrobora as evidências de Furuta (2010), que apontam que a maioria das empresas que constituem Comitês de Auditoria, de 2005 a 2008, possuía um especialista financeiro. Na pesquisa de Chiodini (2010), observou-se que a maioria das empresas que possuem ADRs no mercado americano têm, pelo menos, um especialista financeiro. A KPMG (2009), na $18^{\circ}$ Mesa de Debates composta por profissionais que atuam em Comitês de Auditoria, verificou que apenas 10\% dos participantes não possuem especialistas financeiros nos órgãos em que atuam. Essa recomendação é feita pela Lei Sarbanes-Oxley (SOX). Assim sendo, 6 empresas, mesmo estando submetidas à SOX, não atendem a essa exigência.

A cerca da questão 2 , sobre a existência de pelo menos um membro com conhecimento na área de Contabilidade e Auditoria, 66\%, ou 38 empresas do total da população selecionada, apresentam ambos conhecimentos, de acordo com dados disponibilizados na BMF\&BOVESPA e nos sites das empresas em estudo. Essa exigência é emitida pelo Bacen e pela Susep. A empresa Banrisul, sujeita ao Bacen, é a única deste grupo que não possui pelo menos um membro com conhecimento em Contabilidade e Auditoria.

As questões 3 e 4 são recomendações do IBGC. Na questão 3, observa-se que, em 67\%, ou em 39 empresas do total da população selecionada, não são todos os membros que possuem conhecimentos básicos em Contabilidade e Finanças. Segundo dados divulgados no site da BMF\&BOVESPA, os integrantes da companhia Biosev e CCX apresentam conhecimentos somente na área de Finanças, e na empresa IOCHPE os membros possuem conhecimentos básicos somente em Contabilidade. As empresas que não estão obrigadas a constituir o comitê de auditoria e que por opção atendem às recomendações do IBGC apresentam o maior percentual de membros com conhecimento em ambas as áreas, compreendendo $74 \%$, ou seja, 17 empresas do grupo.

Com relação à questão 4 , cerca de $83 \%$, ou 48 empresas total da população selecionada, possuem pelo menos um membro com maior experiência em Contabilidade e Auditoria ou Gestão Financeira, ou seja, atendem às regras estabelecidas pelo IBGC. 
A Tabela 3 aponta a duração do mandato do comitê de auditoria das 58 empresas que compõem a população selecionada do estudo.

Tabela 3

Mandato do Comitê de Auditoria

\begin{tabular}{|c|c|c|c|c|c|c|}
\hline Período (em anos) & sox & Bacen & sox e Bacen & Susep & IBGC & Total \\
\hline \multirow{2}{*}{1} & 8 & 4 & 3 & 2 & 8 & 25 \\
\hline & $40 \%$ & $50 \%$ & $60 \%$ & $100 \%$ & $35 \%$ & $43 \%$ \\
\hline \multirow{2}{*}{2} & 6 & 2 & 1 & 0 & 8 & 17 \\
\hline & $30 \%$ & $25 \%$ & $20 \%$ & $0 \%$ & $35 \%$ & $29 \%$ \\
\hline \multirow{2}{*}{3} & 1 & 1 & 0 & 0 & 4 & 6 \\
\hline & $5 \%$ & $13 \%$ & $0 \%$ & $0 \%$ & $17 \%$ & $10 \%$ \\
\hline \multirow{2}{*}{4} & 1 & 0 & 0 & 0 & 0 & 1 \\
\hline & $5 \%$ & $0 \%$ & $0 \%$ & $0 \%$ & $0 \%$ & $2 \%$ \\
\hline \multirow{2}{*}{5} & 2 & 1 & 1 & 0 & 0 & 4 \\
\hline & $10 \%$ & $13 \%$ & $20 \%$ & $0 \%$ & $0 \%$ & $7 \%$ \\
\hline \multirow{2}{*}{+ de 5} & 0 & 0 & 0 & 0 & 1 & 1 \\
\hline & $0 \%$ & $0 \%$ & $0 \%$ & $0 \%$ & $4 \%$ & $2 \%$ \\
\hline \multirow{2}{*}{ Indeterminado } & 2 & 0 & 0 & 0 & 2 & 4 \\
\hline & $10 \%$ & $0 \%$ & $0 \%$ & $0 \%$ & $9 \%$ & $7 \%$ \\
\hline
\end{tabular}

Fonte: dados da pesquisa (2015).

Sobre a questão temporal, ou seja, qual a duração do mandato dos membros que formam o comitê de auditoria, observa-se que $43 \%$, ou 25 empresas do total da população selecionada, possuem mandato de 1 ano, e 29\%, ou 17 empresas do total da população selecionada, possuem mandato de 2 anos.

Destaca-se, no Regimento Interno da Empresa Diagnósticos da América S/A (Dasa), do exercício de 2013, que o mandato dos membros possui duração de até 10 anos. Já as empresas que divulgaram no Estatuto Social e/ou Regimento Interno mandato com duração de tempo indeterminado, compreendem Brooksfield, CTEEP, CVC e JBS.

Segundo Beuren, Nass, Theiss e Cunha (2013), a ausência de declaração de prazos de mandato pode representar certa flexibilidade às empresas. De outro lado, isso pode induzir as empresas a não buscarem a renovação dos membros do comitê, o que, possivelmente, prejudica a isenção necessária no desempenho de suas funções, devido a laços que se criam ao longo do tempo. O estabelecimento de parâmetros de período de permanência do comitê de auditoria também é interessante para fins de comparação das suas características em diferentes empresas.

De acordo com as regras do Bacen e Susep, a permanência máxima do mandato deve ser de cinco anos, com retorno após três anos, o que significa que as empresas citadas anteriormente estão, nesse item, em desacordo. Atenta-se para as divergências das informações de duração do mandato divulgadas pelas empresas no Estatuto Social e/ou Regimento Interno e as informações disponibilizadas no site da BM\&FBOVESPA das empresas Banco ABC, Banco Bradesco, Banco do Brasil, Banco Banrisul, BIC Banco, Banco Pan, Banco Pine, Banco Santander, Banco Sofisa e Porto Seguro.

Além disso, o IBGC determina que o mandato deva ser limitado por meio de rodízio automático, constatou-se que $100 \%$, ou 58 empresas do total da população selecionada do estudo, não realizam o rodízio automático, segundo informações divulgadas por meio do Estatuto Social e/ou do Regimento Interno e no site da BM\&FBOVESPA. 
A Tabela 4 apresenta a frequência com que as reuniões são realizadas pelo comitê de auditoria das 58 empresas que compõem a população selecionada neste estudo.

Tabela 4

Reuniões do Comitê de Auditoria

\begin{tabular}{|c|c|c|c|c|c|c|}
\hline Período (em anos) & sox & Bacen & sox e Bacen & Susep & IBGC & Total \\
\hline \multirow{2}{*}{ Bimestral } & 0 & 0 & 0 & 1 & 1 & 2 \\
\hline & $0 \%$ & $0 \%$ & $0 \%$ & $50 \%$ & $4 \%$ & $3 \%$ \\
\hline \multirow{2}{*}{$\begin{array}{c}\text { No mínimo } \\
\text { Bimestral }\end{array}$} & 1 & 0 & 0 & 0 & 1 & 2 \\
\hline & $5 \%$ & $0 \%$ & $0 \%$ & $0 \%$ & $4 \%$ & $3 \%$ \\
\hline \multirow{2}{*}{ Trimestral } & 5 & 4 & 2 & 1 & 9 & 21 \\
\hline & $25 \%$ & $50 \%$ & $40 \%$ & $50 \%$ & $39 \%$ & $36 \%$ \\
\hline \multirow{2}{*}{$\begin{array}{l}\text { No mínimo } \\
\text { Trimestral }\end{array}$} & 2 & 3 & 2 & 0 & 1 & 8 \\
\hline & $10 \%$ & $38 \%$ & $40 \%$ & $0 \%$ & $4 \%$ & $14 \%$ \\
\hline \multirow{2}{*}{$\begin{array}{c}\text { No mínimo } \\
\text { Semestral }\end{array}$} & 0 & 0 & 1 & 0 & 0 & 1 \\
\hline & $0 \%$ & $0 \%$ & $20 \%$ & $0 \%$ & $0 \%$ & $2 \%$ \\
\hline \multirow{2}{*}{ Periódicas } & 3 & 1 & 0 & 0 & 1 & 5 \\
\hline & $15 \%$ & $13 \%$ & $0 \%$ & $0 \%$ & $4 \%$ & $9 \%$ \\
\hline \multirow{2}{*}{ Não consta } & 9 & 0 & 0 & 0 & 10 & 19 \\
\hline & $45 \%$ & $0 \%$ & $0 \%$ & $0 \%$ & $43 \%$ & $33 \%$ \\
\hline
\end{tabular}

Fonte: dados da pesquisa (2015).

Verifica-se maior frequência na realização de reuniões trimestrais em 36\%, ou 21 empresas do total. No Brasil, Silveira e Ito (2008) afirmaram que as empresas sujeitas à SOX apresentam reuniões do comitê de auditoria, com uma média de quase uma reunião por mês. Esse achado não é confirmado nas empresas da amostra, que apresentaram, em sua maioria, a frequência de reuniões trimestrais no grupo de empresas submetidas à SOX. Nesse mesmo estudo, os autores constataram que para as empresas do Novo Mercado, a média aproxima-se de reuniões bimestrais. Porém, nesta amostra somente 3\%, ou 2 empresas, realizam reunião bimestral ou, no mínimo, bimestral.

Segundo as regras do Bacen, IBGC e Susep as empresas devem realizar reuniões também com os auditores independentes. Da análise efetuada, contatou-se que 100\% das empresas realizam reuniões com os auditores independentes, segundo informações divulgadas no Estatuto Social e/ou Regimento Interno. Além disso, as empresas Banco Sofisa, CCR, Sabesp, IOCHPE e Light divulgaram, no Estatuto Social e/ou Regimento Interno, que as reuniões são periódicas, mas não divulgaram o prazo. Segundo achados de Segreti e Costa (2007, pp. 7-8), na pesquisa realizada em 2006, " $72,0 \%$, ou 18 respondentes, indicaram que o comitê de auditoria e os auditores independentes reúnem-se ao menos uma vez a cada trimestre para examinar o escopo de trabalho de auditoria".

Destaca-se um percentual considerável de 33\%, ou 19 empresas da população selecionada, que não consta ou não publicou nenhuma informação sobre a frequência das reuniões no Estatuto Social e/ou no Regimento Interno. 
Em relação à atuação do comitê de auditoria nas empresas pesquisadas, a Tabela 5 apresenta as atribuições recomendadas ao comitê de auditoria.

Tabela 5

Atribuições do Comitê de Auditoria

\begin{tabular}{|c|c|c|c|c|}
\hline $\mathbf{N}^{\circ}$ & Questões & Sim & Não & $\mathbf{N} / \mathbf{C}$ \\
\hline 1 & Recomenda a contratação de auditoria externa? & $\begin{array}{c}45 \\
78 \%\end{array}$ & $\begin{array}{c}0 \\
0 \%\end{array}$ & $\begin{array}{c}13 \\
22 \% \\
\end{array}$ \\
\hline 2 & Os serviços de não auditoria são pré-aprovados pelo comitê de auditoria? & $\begin{array}{c}22 \\
38 \%\end{array}$ & $\begin{array}{c}12 \\
21 \% \\
\end{array}$ & $\begin{array}{c}12 \\
21 \% \\
\end{array}$ \\
\hline 3 & Os auditores encaminham o relatório específico para o comitê? & $\begin{array}{c}44 \\
76 \%\end{array}$ & $\begin{array}{c}0 \\
0 \%\end{array}$ & $\begin{array}{c}14 \\
24 \%\end{array}$ \\
\hline 4 & $\begin{array}{l}\text { Os processos de elaboração e divulgação das demonstrações financeiras } \\
\text { são supervisionadas pelo comitê de auditoria? }\end{array}$ & $\begin{array}{c}38 \\
66 \%\end{array}$ & $\begin{array}{c}2 \\
3 \%\end{array}$ & $\begin{array}{c}18 \\
31 \%\end{array}$ \\
\hline 5 & As demonstrações contábeis são revisadas semestralmente? & $\begin{array}{c}13 \\
22 \%\end{array}$ & $\begin{array}{c}20 \\
34 \%\end{array}$ & $\begin{array}{c}25 \\
43 \%\end{array}$ \\
\hline 6 & O comitê determina um conjunto de procedimentos internos? & $\begin{array}{c}19 \\
33 \% \\
\end{array}$ & $\begin{array}{c}17 \\
29 \%\end{array}$ & $\begin{array}{c}22 \\
38 \%\end{array}$ \\
\hline 7 & É responsável pela eficácia e eficiência dos controles internos? & $\begin{array}{c}18 \\
31 \%\end{array}$ & $\begin{array}{c}11 \\
19 \% \\
\end{array}$ & $\begin{array}{c}29 \\
50 \% \\
\end{array}$ \\
\hline 8 & $\begin{array}{l}\text { Verifica o cumprimento de dispositivos legais, normativos, regulamentos } \\
\text { e códigos internos? }\end{array}$ & $\begin{array}{c}41 \\
71 \%\end{array}$ & $\begin{array}{c}1 \\
2 \%\end{array}$ & $\begin{array}{c}16 \\
28 \%\end{array}$ \\
\hline 9 & Verifica o cumprimento do código de ética pelos administradores? & $\begin{array}{c}13 \\
22 \%\end{array}$ & $\begin{array}{c}11 \\
18 \%\end{array}$ & $\begin{array}{c}34 \\
59 \%\end{array}$ \\
\hline 10 & Verifica o cumprimento do código de conduta? & $\begin{array}{c}14 \\
24 \%\end{array}$ & $\begin{array}{c}5 \\
8 \%\end{array}$ & $\begin{array}{c}39 \\
67 \% \\
\end{array}$ \\
\hline 11 & O comitê estabelece e divulga regulamentos e códigos internos? & $\begin{array}{c}24 \\
41 \%\end{array}$ & $\begin{array}{c}10 \\
17 \%\end{array}$ & $\begin{array}{c}24 \\
41 \%\end{array}$ \\
\hline 12 & Adota procedimentos para receber e tratar queixas? & $\begin{array}{c}20 \\
34 \%\end{array}$ & $\begin{array}{c}9 \\
15 \%\end{array}$ & $\begin{array}{c}29 \\
50 \%\end{array}$ \\
\hline
\end{tabular}

Fonte: dados da pesquisa (2015).

A recomendação da contratação da auditoria externa é exposta por todas as regras incorporadas no mercado acionário brasileiro. Observa-se que $78 \%$, ou 45 empresas do total da população selecionada, divulgam que uma das atribuições do comitê de auditoria é recomendar a contratação de auditores independentes. Destaca-se que todas as empresas submetidas ao Bacen ou à Susep estão nesse grupo, e $22 \%$, ou 13 empresas, não divulgaram essa informação, sendo que 5 são submetidas à SOX e 8, ao IBGC.

Na questão 10,24\%, ou 14 empresas do total da população selecionada, adotam um Código de Conduta. Destacam-se 8\%, ou 5 empresas, que estão em desacordo com os regulamentos do IBGC, e compreendem a B2W - Companhia Digital e a Ser Educacional S.A., submetidas ao IBGC; BRF S.A e Odontoprev S.A., submetidas à SOX; e o Itaú Unibanco Holding S.A., submetido à SOX e Bacen, conjuntamente.

Já na questão 11 , em $41 \%$, ou 24 empresas do total da população selecionada, o comitê de auditoria estabelece e divulga regulamentos e códigos internos. 
Verifica-se, na questão 12, que $34 \%$, ou 20 empresas do total da população selecionada, adotam procedimentos para receber e tratar queixas. Destaca-se que em $50 \%$ da amostra não se encontaram evidências sobre essa informação. No estudo de Segreti e Costa (2007, p. 8), "60,0\%, ou 15 respondentes, informaram haver participação real do comitê de auditoria nas fases do processo para receber e tratar denúncias de irregularidades relacionadas a questões contábeis, controles internos e de auditoria”.

Em relação às obrigações do comitê de auditoria, a Tabela 6 apresenta as perguntas de investigação recomendadas ao comitê de auditoria.

Tabela 6

Obrigações do Comitê de Auditoria

\begin{tabular}{|c|c|c|c|c|}
\hline $\mathbf{N}^{\circ}$ & Questões & Sim & Não & $\mathrm{N} / \mathrm{C}$ \\
\hline 1 & Elabora relatório de comitê de auditoria? & $\begin{array}{c}45 \\
78 \%\end{array}$ & $\begin{array}{c}0 \\
0 \%\end{array}$ & $\begin{array}{c}13 \\
22 \%\end{array}$ \\
\hline 2 & Elabora semestralmente o relatório de comitê de auditoria? & $\begin{array}{c}18 \\
31 \%\end{array}$ & $\begin{array}{c}18 \\
31 \%\end{array}$ & $\begin{array}{c}22 \\
38 \%\end{array}$ \\
\hline 3 & Possui regimento interno? & $\begin{array}{c}34 \\
59 \%\end{array}$ & $\begin{array}{c}1 \\
2 \%\end{array}$ & $\begin{array}{c}23 \\
40 \%\end{array}$ \\
\hline
\end{tabular}

Fonte: dados da pesquisa (2015).

Observa-se, na questão 1, que 78\%, ou 45 empresas do total da população selecionada, divulgam como uma das obrigações do comitê de auditoria a elaboração do relatório de comitê de auditoria. Destaca-se que todas as empresas submetidas ao Bacen e a Susep estão nesse grupo e das 13 empresas, ou 22\% da população selecionada, que não divulgaram essa informação, 5 empresas são submetidas à SOX e 8 empresas ao IBGC. Essa é uma exigência do Bacen e da Susep.

Na questão 2, sobre a elaboração semestral do relatório de comitê de auditoria, 38\%, ou 22 empresas selecionadas, não divulgam ou não constam essa informação por meio do Estatuto Social e/ou do Regimento Interno. Das empresas que elaboram, semestralmente, o relatório, ou seja, $31 \%$, ou 18 empresas do total da população selecionada, 2 empresas são submetidas à SOX, 8 empresas ao Bacen, 4 empresas à SOX e ao Bacen, conjuntamente, 2 empresas ao IBGC e 2 empresas, ou 100\% do grupo, são submetidas à Susep.

Já na questão 3, sobre a existência de regimento interno do comitê de auditoria, 59\%, ou 34 empresas, atendem à exigência do Bacen e Susep. Atenta-se para o descumprimento da regra a empresa JHSF Participações S.A., que não apresenta e/ou não disponibiliza regras para o funcionamento do comitê de auditoria. 
Por fim, na Tabela 7, apresentam-se os índices de adequação do comitê de auditoria encontrados em cada empresa (IA), com informações do nível diferenciado de governança corporativa da BM\&FBOVESPA (NDGC) e a regra que a norteia.

Tabela 7

Índice de Adequação do Comitê de Auditoria à Governança Corporativa

\begin{tabular}{|c|c|c|c|c|c|c|c|c|c|c|c|}
\hline NDGC & Norma & Empresa & IA & NDGC & Norma & Empresa & IA & NDGC & Norma & Empresa & IA \\
\hline N1 & Bacen e SOX & Itau & 23 & NM & $\begin{array}{c}\text { Bacen e } \\
\text { SOX }\end{array}$ & Cielo & 16 & N1 & IBGC & $\begin{array}{l}\text { Magazine } \\
\text { Luiza }\end{array}$ & 12 \\
\hline NM & sox e Bacen & $\begin{array}{c}\text { Parana } \\
\text { Banco }\end{array}$ & 23 & NM & IBGC & EDP & 16 & NM & SOX & JBS & 11 \\
\hline NM & Susep & Sul America & 23 & NM & IBGC & Petrorio & 16 & N2 & IBGC & $\mathrm{B} 2 \mathrm{~W}$ & 10 \\
\hline NM & Bacen & Banco Pan & 22 & N2 & Ssusep & Porto Seguro & 16 & NM & sox & GOL & 10 \\
\hline NM & Bacen & ABC Banco & 21 & N1 & sox & TIM & 16 & NM & sox & Suzano & 10 \\
\hline NM & Bacen e SOX & Santander & 20 & N1 & IBGC & TOTVS & 16 & NM & SOX & Eneva & 9 \\
\hline N1 & IBGC & Cetip & 20 & N1 & IBGC & CCX & 15 & N1 & IBGC & Alupar & 7 \\
\hline NM & SOX & OdontoPrev & 20 & NM & sox & Gafisa & 15 & N1 & IBGC & Tupy & 7 \\
\hline NM & Bacen & BB & 19 & NM & IBGC & Rodobens & 15 & $\mathrm{~N} 2$ & IBGC & $\mathrm{CCR}$ & 6 \\
\hline NM & Bacen & BICBanco & 19 & $\mathrm{~N} 2$ & IBGC & Usiminas & 15 & NM & IBGC & Ecorodovias & 6 \\
\hline NM & Bacen & Banco Pine & 19 & NM & SOX & BRF & 14 & NM & IBGC & Kroton & 6 \\
\hline NM & Bacen & Bovespa & 19 & NM & IBGC & Dasa & 14 & $\mathrm{~N} 2$ & IBGC & Tarpon & 6 \\
\hline $\mathrm{N} 2$ & Sox & Sabesp & 18 & N1 & IBGC & Paranapanema & 14 & NM & sox & Brookfield & 5 \\
\hline N1 & IBGC & Lojas Renner & 18 & N2 & IBGC & Ser Educacional & 14 & NM & SOX & MMX & 5 \\
\hline NM & Bacen e SOX & Bradesco & 17 & NM & SOX & Cosan & 13 & NM & IBGC & CVC & 4 \\
\hline NM & Bacen & Banrisul & 17 & NM & SOX & Pão de Açúcar & 12 & $\mathrm{~N} 2$ & SOX & Equatorial & 4 \\
\hline NM & SOX & $\begin{array}{l}\text { Fibria e } \\
\text { Celulose } \\
\end{array}$ & 17 & N2 & SOX & IOCHPE & 12 & NM & SOX & Marfrig & 4 \\
\hline $\mathrm{N} 2$ & Bacen & Banco Sofisa & 16 & N1 & IBGC & JHSF & 12 & NM & sox & Celesc & 3 \\
\hline NM & IBGC & Biosev & 16 & NM & SOX & Light & 12 & NM & IBGC & Cteep & 1 \\
\hline N1 & SOX & Copel & 16 & - & - & - & - & - & - & - & - \\
\hline
\end{tabular}

Fonte: dados da pesquisa (2015).

Por meio de média aritmética, encontrou-se o nível de adequação médio nas empresas selecionadas de $50 \%$, ou seja, 13 pontos do total de 26 . Já com a análise quartil, pode-se verificar a relação dos índices encontrados com as regras e com os NDGC.

Observa-se que as empresas que pontuaram entre 26 - 17 (quartil superior) obtiveram o melhor nível de adequação. Assim, as instituições financeiras, sujeitas ao Bacen, e as instituições de previdência e de seguros, sujeitas à Susep, formam o grupo que está mais adequado ao conjunto de regras acerca do comitê de auditoria.

As empresas que pontuaram entre 17,25 - 9,76 (segundo quartil) tiveram uma aderência mediana, e as empresas que pontuaram entre 9,75 - 0 (primeiro quartil), grupo formado pelas empresas que estão submetidas à SOX e ao IBGC, representam os índices mais baixos da população selecionada.

Os achados apontam que empresas submetidas a um agente regulamentador tendem a se preocupar mais com o cumprimento das regras de governança corporativa. Antunes, Honorato e Antunes (2007, p. 3) afirmam "que as melhores práticas de governança migram da condição de aspiração de investidores para a obrigatoriedade legal". O que se entende que com normas legais há um avanço no atendimento à governança corporativa. 
Sobre a relação entre o índice obtido e os níveis de governança corporativa, observa-se que é fraca, logo não possibilita constatar relação entre os níveis diferenciados de governança e o índice de adequação, ou seja, possuir classificação no novo mercado não garante uma boa adequação às normas referentes ao comitê de auditoria.

\section{Conclusão}

O estudo teve por objetivo identificar qual o nível de adequação dos comitês de auditoria das empresas dos níveis diferenciados da BM\&FBOVESPA às regras da SOX, Bacen, Susep e IBGC. Para alcançar esse objetivo, foi construído um índice por meio da aplicação de um check-list baseado nas regras que atingem as empresas brasileiras.

O nível de adequação médio encontrado nas empresas da amostra foi de 50\% (13 de 26 questões), com a máxima de $88 \%$ (23 questões) e a mínima de $4 \%$ (1 questão). Constatou-se que as empresas sujeitas às regras do Bacen e Susep formam o grupo com a maior adequação enquanto as empresas submetidas à SOX e as que são desobrigadas a constituir o comitê de auditoria apresentaram os índices mais baixos da amostra.

Pode-se inferir, com os achados, que empresas submetidas a um agente regulamentador tendem a se preocupar mais com a governança corporativa. Infere-se também que pertencer aos níveis mais altos de governança corporativa da BM\&FBOVESPA não é prorrogativa para melhor adequação às práticas de governança referente ao comitê de auditoria.

Um fato em destaque é que algumas empresas, mesmo sendo obrigadas a atenderem determinadas regras, não o fazem. É o caso da independência dos membros, quesito que, a apesar de toda a população selecionada ter que atendê-lo, $86 \%$ dos comitês são compostos por membros que não são independentes. No que se refere à qualificação dos membros, seis empresas, mesmo estando submetidas à SOX, não possuem especialista financeiro, e uma empresa sujeita ao Bacen não possui pelo menos um membro com conhecimento na área de Contabilidade e Auditoria, conforme exigido pelos órgãos, respectivamente.

Destaca-se que, durante a coleta dos dados, constataram-se divergências de informações referentes à duração do mandato dos comitês divulgadas pelas empresas no Estatuto Social e/ou nos Regimento Interno e as informações disponibilizadas no site da BM\&FBOVESPA, ou seja, é possível que tenha havido o descumprimento do regimento interno em alguns casos.

No que tange às atribuições e obrigações do comitê de auditoria, atenta-se para a dificuldade de se encontrarem dados disponíveis. Essas informações geralmente são divulgadas no Relatório do Comitê ou Estatuto Social e/ou no Regimento Interno e, em $22 \%$ e $40 \%$ das empresas, esses documentos, respectivamente, não foram disponibilizados. Essa situação infringe um dos princípios da governança corporativa, que é o da transparência, e impossibilita o acompanhamento dos interessados nas funções do comitê de auditoria.

Desse modo, o estudo possibilitou demonstrar como se encontra a atual estrutura do comitê de auditoria das empresas dos níveis diferenciados de governança corporativa na BMF\&BOVESPA, contribuindo para as discussões e disseminação do tema entre a comunidade acadêmica e entre os agentes do mercado acionário que procuram mecanismos que forneçam segurança e credibilidade aos stakeholders.

Considerando-se a limitação da pesquisa, recomenda-se ampliar o número de empresas, incluindo as demais companhias da BM\&FBOVESPA que possuem comitê de auditoria; realizar o estudo em empresas que não possuem ações negociadas em bolsa de valores, a fim de verificar a adequação às práticas de governança corporativa; e, em empresas do mercado acionário que não possuem comitê de auditoria conhecer as razões da ausência desse órgão e/ou suas características. 


\section{Referências}

Antunes, J., Honorato, W. R., \& Antunes, G. M. B. (2007). A importância da atuação dos comitês de auditoria nos trabalhos dos auditores independentes de companhias abertas brasileiras. Anais do Congresso do Instituto Internacional de Custos, Universidade de Jean Moulin Lyon, Lyon, França, 10.

Beuren, I. M., Nass, S., Theiss, v., \& Cunha, P. R. da. (2013). Caracterização Proposta para o Comitê de Auditoria no Código de Governança Corporativa do Brasil e de Outros Países. Revista de Educação e Pesquisa em Contabilidade. 7(4), pp. 407-423. doi: 10.17524/repec.v7i4.989.

BM\&FBOVESPA (2014). Recuperado de http://www.bmfbovespa.com.br/pt_br/listagem/acoes/segmentos-de-listagem/sobre-segmentos-de-listagem/

Bronson, S. N., Carcello, J. V., Hollingsworth, C. W., \& Neal, T. L. (2009) Are fully independent audit committees really necessary? Journal of Accounting and Public Policy, 28(4), pp. 265-280. doi:10.1016/j. jaccpubpol.2009.06.001.

Carcello, J. V., Hermanson, D. R., \& Neal, T.L. (2002). Disclosures in audit committee charters and reports. Accounting Horizons, 16(4), pp. 291-304.

Carcello, J. V., Neal, T. L. (2000). Audit Committee composition and auditor reporting. The Accounting Review, 75(4), pp. 453-467. doi: 10.2139/ssrn.229835.

Chiodini, D. M. (2010). Adequação das companhias que atuam no Brasil à governança corporativa: o Comitê de Auditoria. Monografia, Universidade Federal de Santa Catarina, Florianópolis, SC, Brasil. Recuperado de: https://repositorio.ufsc.br/bitstream/handle/ 123456789/120820/284147. pdf? sequence $=1$ \&isAllowed $=y$

Conselho Monetário Nacional (CMN) (2004). Resolução n. 3.198, de 27 de maio de 2004. Brasília, Brasil.

Conselho Nacional De Seguros Privados (CNSP) (2004). Resolução n.118, de 22 de dezembro de 2004. Rio de Janeiro, Brasil. Recuperado de http://www.susep.gov.br/textos/resol118-04.pdf

Felo, A. J., Krishnamurthy, \& S., Solieri, A. S. (2003) Audit committee characteristics and the perceived quality of financial reporting: an empirical analysis. doi: 10.2139/ssrn.401240.

Furuta, F. (2010). A Relação das Características das Empresas com a Adoção do Comitê de Auditoria x Conselho Fiscal Adaptado. Tese de doutorado, Universidade de São Paulo, São Paulo, SP, Brasil. Recuperado de http://www.teses.usp.br/teses/disponiveis/12/12136/tde-19042010-104120/

Gil, A. C. (2002). Como elaborar projetos de pesquisa. (4ª ed.). São Paulo: Atlas.

Instituto Brasileiro de Governança Corporativa (2009). Guia de orientações para melhores práticas de Comitês de Auditoria. Recuperado de http://www.ibgc.org.br/userfiles/files/Guia_7_.pdf

Jensen, M., \& Meckling, W. (1976). Theory of the firm: managerial behavior, agency costs and ownership structure. Journal of Financial Economics, 3, pp. 305-360. doi: 10.1016/0304-405X(76)90026-X.

KPMG (2009) Conselho Fiscal e Comitê de Auditoria: Responsabilidades, potenciais conflitos e lições aprendidas - 18a Mesa de Debates. Recuperado de http://www.kpmg. com.br/aci/publicacoes/2009/18_ Mesa_Debates.pdf.

Lakatos, E.M., \& Marconi, M.A. (2001). Fundamentos de metodologia cientifica. (4a ed.). São Paulo: Atlas.

Peleias, I. R., Segreti, J. B., \& Costa, C. de A. (2009). Comitê de auditoria ou órgãos equivalentes no contexto da Lei Sarbanes-Oxley: estudo da percepção dos gestores de empresas brasileiras emitentes de American Depositary Receipts-ADRs. Contabilidade Vista \& Revista, 20(1), pp. 41-65.

PricewaterhouseCoopers (2007). Comitês de auditoria no Brasil - Melhores práticas de governança corporativa: $O$ desafio continua ( $2^{\mathrm{a}}$ ed.). Brasil: PricewaterhouseCoopers. 
Raghunandan, K.; \& Rama, D. (2007). Determinants of Audit Committee diligence. Accounting Horizons. 21, pp. 265-297. doi: 10.2308/acch.2007.21.3.265.

Richardson, R. J. (2008). Pesquisa social: métodos e técnicas. (3a . ed.). São Paulo: Atlas.

Santos, A. G. dos. (2009). Comitê de auditoria: uma análise baseada na divulgação das informações de empresas brasileiras. Dissertação de mestrado, Faculdade de Economia, Administração e Contabilidade, Universidade de São Paulo, São Paulo, SP, Brasil. Recuperado de: http://www.teses.usp.br/teses/ disponiveis/12/12136/tde-07102009-122913/

Segreti, J. B., \& Costa, C. A. (2007). Pesquisa Exploratória sobre a Implantação do Comitê de Auditoria em Empresas Brasileiras conforme Lei Sarbanes-Oxley. Encontro da ANPAD, Rio de Janeiro, RJ, Brasil, 31.

Sharma, V., Naiker, V., Lee, B. (2009). Determinants of Audit Committee Meeting Frequency: Evidence from Voluntary Governance System. Accounting Horizons. 23(3), pp. 245-263. doi: 10.2308/ acch.2009.23.3.245.

Silveira, A. Di M. da, Ito, S. (2008). A Governança Corporativa e o Mercado de Capitais: Um panorama atual das corporações brasileiras na Bovespa e nas Bolsas norte-americanas. Recuperado de http:// www.kpmg.com.br/publicacoes/kpmg_estudo_20f_2008_final.pdf

Silveira, A. di M. da. (2004). Governança corporativa e estrutura de propriedade: Determinantes e relação com o desempenho das empresas no Brasil. Tese de doutorado, Faculdade de Economia, Administração e Contabilidade da Universidade de São Paulo, São Paulo, SP, Brasil. Recuperado de http:// www.teses.usp.br/teses/disponiveis/12/12139/tde-23012005-200501/pt-br.php

Souza, P. C. da S. S. de. (2010). Práticas do comitê de auditoria: evidências de empresas brasileiras. Dissertação de mestrado, Faculdade de Economia, Administração e Contabilidade, Universidade de São Paulo, São Paulo, SP, Brasil. Recuperado de http://www.teses.usp.br/teses/disponiveis/12/12136/ tde-04042011-202813/ 